\title{
PHYLOGENETIC SPECULATION OF THE TUNICATA
}

AUTHOR(S):

Tokioka, Takasi

CITATION:

Tokioka, Takasi. PHYLOGENETIC SPECULATION OF THE TUNICATA.

PUBLICATIONS OF THE SETO MARINE BIOLOGICAL LABORATORY 1971, 19(1): 43-63

\section{ISSUE DATE:}

1971-06-30

URL:

http://hdl.handle.net/2433/175655

RIGHT: 


\section{PHYLOGENETIC SPECULATION OF THE TUNICATA ${ }^{\text {t) }}$}

\section{TAKASI TOKIOKA}

Seto Marine Biolcgical Laboratory

With 3 Diagrams

CONTENTS

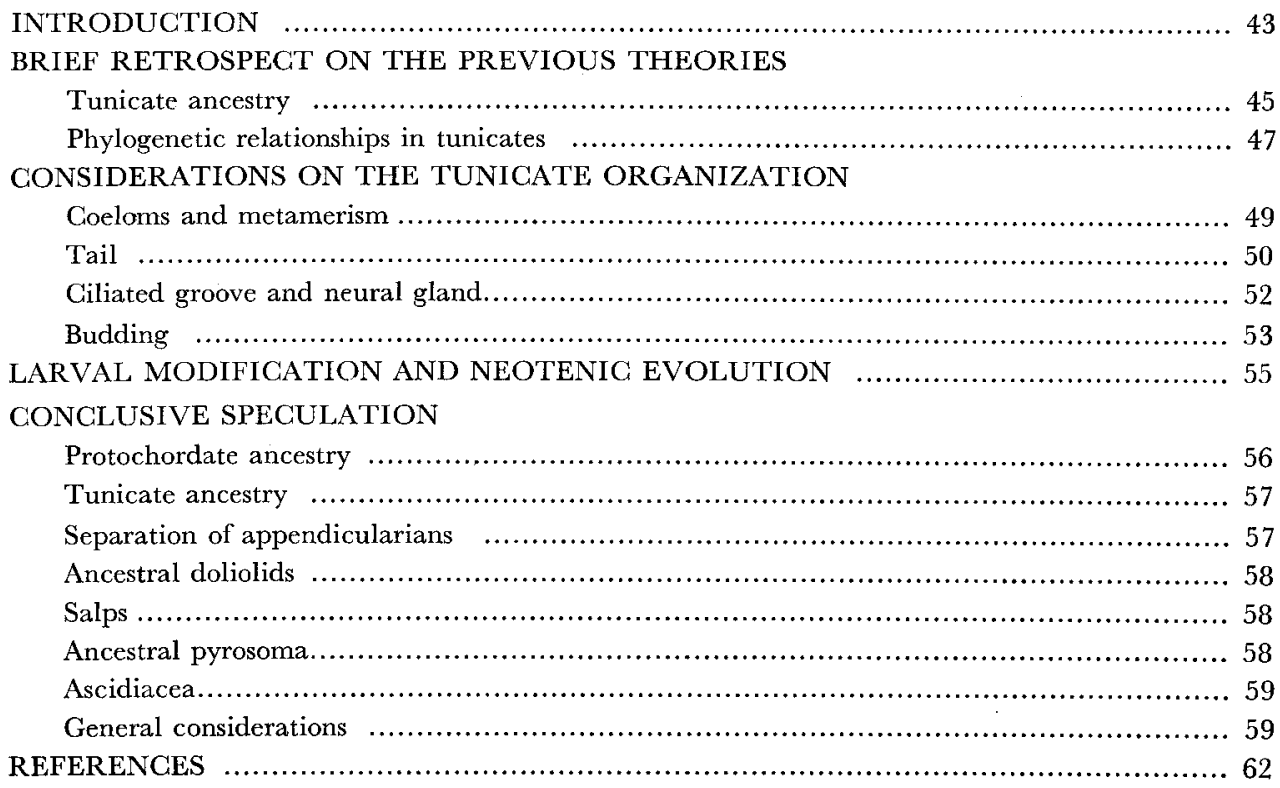

\section{INTRODUCTION}

It must be natural that the long term of taxonomical researches on tunicates, both pelagic and sessile, have instigated me to give my consideration on the phylogenetic relationships among the groups of Tunicata and also on the possible ancestry of this class of the phylum Protochordata. Really it must be a big work beyond my ability to do this as comprehensively and satisfactorily as in several eminent works done by previous researchers. Firstly, it is evidently impossible for me to read over all published papers concerning the present problem and to understand them

1) Contributions from the Seto Marine Biological Laboratory, No. 547.

Publ. Seto Mar. Biol. Lab, XIX (1), 43-63, 1971. (Article 5) 
properly. However, as I have been working on the taxonomy of tunicates, the hypotheses presented by those specialists who were or have been devoted themselves to the systematic studies of tunicates are very convincing to me, thus naturally $I$ have studied most earnestly the papers of Seeliger (1893-1907), Garstang (1928), Lohmann (1933), Neumann (1934-35), Ihle (1935) and Berrill (1950) and learned very many other opinions through these papers. Among them, the theory of Garstang going into details was especially the most impressive to me in its comprehensiveness, though unfortunately I could not agree with him in very many parts of it. In addition to these, the consideration of Barrington (1965) on the Hemichordata and Protochordata stimulated me very much. The opinions of Hyman met with on many pages of her monumental work "The Invertebrates" were very suggestive to me, too (for instance, vol. 5, 1959).

Reading through those papers, it seems that all materials necessary to construct any kind of phylogenetic theories are already ready, and every way of combining or arranging them, possibly acceptable, has been established already, too. Then, seemingly new opinions are allowable only as to the progressive direction of phylogenetic relations found between the subordinate groups of Tunicata.

Recently, however, two very important papers appeared one after the other. One is the IVANov's paper (1965) reporting the occurrence of about 23 segments in the posterior distal portion of the pogonophore, Siboglinum caulleryi and the other is the Gutmann's paper (1966) suggesting that the myomeric musculature of fishes is evidently originated from the metameric coeloms of some precursing segmented animals of fishes. As the presence or absence of coeloms and metamerism is the most important structural feature in the ancestral tunicates, these two papers, especially the former, seem to present a very significant new material or at least can be very effective when the progressive direction of phylogenetic relations is discussed among the members of Tunicata. On the background roughly mentioned above, I have tried to construct my own speculation on the phylogenetic relationships in Tunicata and further in Protochordata, which will be shown later in the chapter of the conclusive speculation.

As the fossils of a possible old appendicularian were found in the middle Cambrian, the differentiation to main groups of Tunicata, hence the separation between the two stems respectively leading to amphioxus and tunicates must have been achieved in much earlier era, then it will be hopeless to obtain any palaeontological records which may be significant to prove any theory. Thus, the speculation is constructed wholly on the basis of comparative anatomy and comparative embryology. As to the former the concept of latent homology which is referred to by BARRINGTON in his book (pp. 165-166) much affected me, and as to the latter the abbreviations and modifications of larval development, some of which may be adaptive and characteristic to respective animals, were kept in mind at any discussions. Such a speculation can never be constructed independent of my own concept of the so-called Deuterostomia and also of my own interpretation of the history up to the Deuterostomia. To these, 
however, I will try to refer in a future paper, though of course they will have to be more imaginary.

\section{BRIEF RETROSPECT ON THE PREVIOUS THEORIES}

Tunicate ancestry: The first must be to reflect upon the ancestral tunicates. There have been prevailing two opinions. One is the supposition of a free-swimming ancestor, while in the other the ancestor is considered to be a sessile form.

(1) Free-swimming ancestors. For DARwin who mentiond in Part I Chapter 6, on the affinity and genealogy of man, of his "The Descent of Man" as "Thus, if we may rely on embryology, ever the safest guide in classification, it seems that we have at last gained a clue to the source whence the Vertebrata were derived", the chordate ancestor was a free-swimming organism and the adult ascidian was a sessile and retrograde interpolation in the life history. For Herdman (1904), too, the ascidians were the animals degenerated from a tailed, free-swimming primitive ancestral form, being provided with the notochord in the tail. Seeliger (1885) supposed that both the sessile tunicates (ascidians) and pelagic tunicates had derived from a free-swimming stem form something like the appendicularians and ascidian larvae, but without any ability of asexual reproduction by budding. Lastly, according to LoHmann (1933) who regarded the so-called retrogressive features found in the ascidians and thaliaceans as the signs of primitiveness but really not of retrogression, the tunicate ancestor was free-swimming and provided with the tail penetrated with the notochord and furnished with the longitudinal muscles, but yet without the peribranchial cavity (atrium) in the anterior half of the body (trunk) whose epidermis was secreting a gelatinous cuticle; neither coelom nor metamerism was found in it and budding was not seen, either. InLE (1935) accepted nearly wholly the hypothesis of LoHmann, but protesting only against that the ancestor was wholly devoid of coeloms. According to IHLE, the ancestor must be provided with coeloms as the Cephalochordata, another member of the Protochordata, evidently forms coeloms and the mesoderm formation in ascidians is done in the way just the same as in amphioxus.

(2) Sessile ancestors. Against earlier and many German researchers, very strangely modern English researchers are seemingly supporting the theory that the tunicate ancestor was a sessile or semisessile animal with a pelagic larva. VAn Name (1921) suggested a sessile tunicate ancestor and further a sessile and colony-forming chordate stem form because of budding ability retained in the tunicates; he considered budding to be a very primitive nature limited to sessile animals. The most claborated hypothesis as to budding in the tunicates must be the opinion of Garstang (1928). He proposed a progressive evolution through the steps from the Echinodermata to the Hemichordata, then to the Protochordata, and lastly leading to the Vertebrata. He imagined a pterobranch-like sessile (or semisessile) ancestral animal derived, by a significant larval modification, from some echinoderm. Thus, this ancestor was 
supposed by him to produce a larva which was provided with the features of both tornaria and larvae of some eleuterozoan of Echinodermata, the potencies of an evolution in the ascidian direction, an extension of the larval life and a trend toward the adoption of independent activity, and further with the habit of metamorphosis. This ancestor developed on one way to the Pterobranchia of Hemichordata and further to the free-living enteropneusts, but on the other way along the chordate stem. And the progressive evolution to the Tunicata was achieved by successive morphological modifications occurred mainly on the free-swimming larvae. Further, the line to the Vertebrata was derived from a very early stage of the chordate stem advancing from the ancestor to the Tunicata, the stage which might already be regarded essentially as a primitive ascidian. The evolutionary modifications on this line were achieved also by neoteny, namely the combination of the larval organization and sexual maturation, in other words retaining the organization of free-swiming larvae but losing the sessile life of adults. The Cephalochordata which was regarded by GARSTANG evidently as a paedomorphic representation was considered to be the animal retrograded towards a semi-sedentary life from the vertebrate line. Thus, the protochordate ancestor, namely the common ancestor of the Cephalochordata and Tunicata, was according to GARSTANG essentially a small stalked primitive ascidian, of which the pharynx was provided with 2 or 3 pairs of U-shaped gill-slits and the stalk was issued from the body part postero-ventral to the endostyle and first included within it only the mesoderm as in the stalk of pterobranchs, but later, in addition, the regenerative diverticulae from the pharynx and peribranchial cavities (lateral atriae). As seen clearly in these supposed processes, the vertebrate metamerism, and then naturally the coelomic (locomotive) metamerism of amphioxus, was not the intrinsic structure but of a secondarily acquired nature in his opinion. From a biological point of view, the above-mentioned evolutionary process was a series of changes from a plankton-feeding life (echinoderm larvae) to a sessile life with acquisition of the external ciliated tentacles and food grooves (pterobranchs) and ending to a free-swimming (pelagic tunicates and cephalochordates) life with acquisition of the endopharyngeal apparatuses comprising the gill-slits and endostyle as the most significant elements.

BARRington (1965) seems to admit roughly the opinion of Garstang, but rejecting the antecedency of the Echinodermata, he expresses his idea as follows: The Echinodermata and the Pterobranchia of Hemichordata share a common ancestral form which was sessile or semisessile, collecting their food externally and with an unspecialized larva that might have been derived from a simple ciliated form like the larvae of modern echinoderms and enteropneusts, and the free-living Enteropneusta was derived from the pterobranch-like ancestor by neoteny (p. 60, line 36). The urochordate-line was seemingly originated with close relation to the ancestral hemichordate which must be showing already the pharyngotremy, the formation of gillslits, and both the Cephalochordata and Vertebrata had a common origin from the 
stock which was derived from the urochordate-line and their morphological differentiation was achieved by neoteny. BARRINGTON considers that the urochordates were originally provided with coeloms, because he takes the reduction of coelom as one of the signs of regression associated with the sessile life (fig. 7 on p. 16).

Hyman (1959) also admitted the derivation of the Enteropneusta from the pterobranch-like form, but protested definitely against the opinion of GARsTANG that the Hemichordata was derived from the Echinodermata. According to her, the common ancestral stock gave off the echinoderms as a blind branch, then continued along its main line of evolution to hemichordates and chordates (p. 199, lines 11-14).

Phylogenetic relationships in the Tunicata: Regardless of the difference of the life mode (sessile or free-swimming) of supposed protochordate ancestors, it is seemingly generally accepted that the ancestral tunicate was a sessile primitive ascidian. Simpler structures in the adult ascidian (simplification of the nervous system, reduction of sensory organs and excretory organs, and complete absence of metamerism) were retrograde features for HeRDMAN and others, but primitive (but never degenerated) features for Garstang, Lohmann and others.

Seeliger (1893-1907) and Lommann (1933) agreed with each other in supposing that the free-swimming tunicate ancestor issued first the line of free-swimming appendicularians, then settled on the substratum to enter the sessile life by losing the tail and acquiring the structure of recent ascidians, and that the thaliaceans were derived from the still pelagic ancestor (SEELIGER) or from such a sessile form as mentioned above (Lohmann). Grobeen (1882) also considered that the Thaliacea, inclusive of pyrosoma, was derived from a sessile ancestor something like the compound ascidians. Ihle (1935) agreed with LoHmann in admitting that the Thaliacea was derived from the sessile ascidian by neoteny.

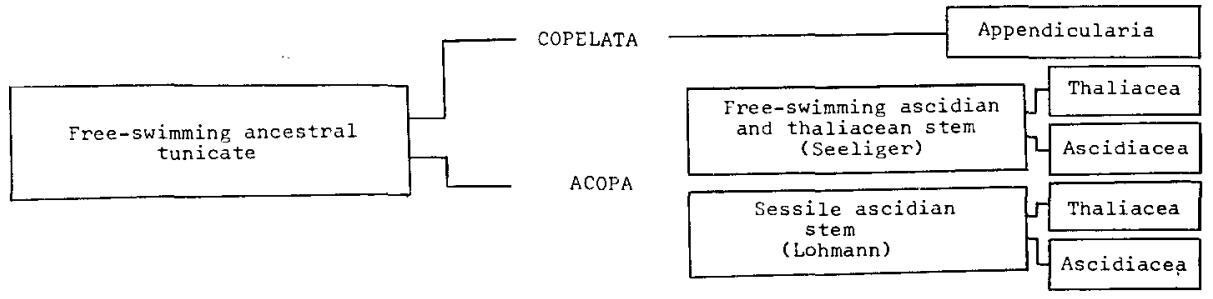

Diagram 1. Phylogeny of the Tunicata, after Seeliger and Lohmann.

For English specialists (GARstang, Berrill, and BARrington) who were or are maintaining the opinion that the ascidians were derived from a sessile primitive tunicate with budding ability and the tadpole larva was born newly in the group of ascidians, both the appendicularians and thaliaceans must be inevitably derived from the ascidian ancestry. GARSTANG recognizing the primitiveness of budding in Thaliacea, considered that the Thaliacea and Ascidiacea were derived independently 
from the primitive ancestral tunicate and the Appendicularia, noted by retaining the larval organization, was differentiated from the thaliacean stock by neoteny. Similarly, Berrill (1950, p. 269) admits the idea that the Ascidiacea was differentiated from the fixed ascidian ancestry by subdivision of the protostigmata, while the compact colonial pyrosoma-like ancestor derived separately from the same ancestry was branched into two lines, one leading to the Pyrosomata and the other to the doliolumlike ancestor which further was subdivided into the doliolum and salpa-lines. His concept of the phylogeny in the Thaliacea is an inheritance from Metcialf (1918) as stated by him (1950, p. 268), and it can be traced back to the opinions of IHLE, Grobben, Uljanin (1884), and Seeliger who did not, however, admit the antecedency of doliolums to salps. LoHmann regarded pyrosoma as an intermediate between the ascidians and the stock comprising sapla and doliolum. BERRILl regards the Appendicularia as a primarily neotenic form, not primitive but very specialized, but gives no definite relation between it and other groups of the Tunicata.

BARrington (1965) seems to admit that the sessile ascidian antedated the Thaliacea and Larvacea (p. 86, lines 21-23).

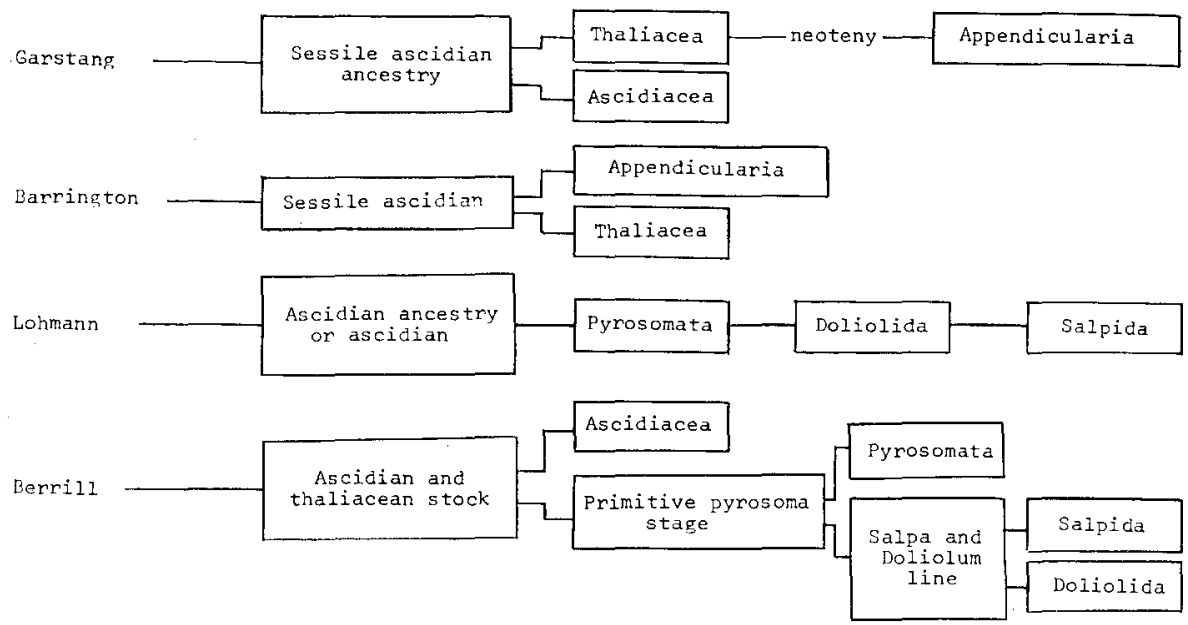

Diagram 2. Phylogeny of the Tunicata, especially of the Thaliacea, after Garstang, Lohmann, Berrill and Barrington. Salpa and doliolum line in the phylogenetic system of BERRILL means the doliolum-like ancestor as stated in the text.

Neumann (1934) was the only one of the systematists of the tunicates, who supported the opinion of SEeLiger that the Thaliacea was derived from the pelagic ancestor.

To make further discussions easier, some points, seemingly important for explaining my own opinion, may better be summarized as follows: 
(Ia) Free-swimming ancestry of tunicates Darwin, Herdman, Seelrger, Lohmann, IHLE.

(1b) Sessile ancestry of tunicates Van Name, Garstang, Berrill, BarrINGTON.

(2a) Coeloms in ancestral tunicates IHLE, BARRINGTON.

(2b) Neither coelom nor metamerism in ancestral tunicates..... LOHMANN.

(2c) Incipient (secondary) metamerism in tunicates Garstang.

(3a) Thaliacea and Ascidiacea derived from a common free-swimming ancestor Seeliger, Neumann.

(3b) Thaliacea and Ascidiacea derived from a common sessile ancestor. GaRstang.

(3c) Thaliacea derived from the sessile ascidian or its primitive form

Lohmann, Ihle, Berrill, Barrington.

(4a) Progressive evolution from pyrosoma to doliolum and further to salpa

Grobben, Metgalf, Ihte, Berrill.

(4b) Doliolum- and salpa lines issued separately from pyrosoma

Seeliger.

(4c) Common stock of salpa and doliolum derived from pyrosoma.......
LoHMAnN.

(5a) Appendicularia as an earlier derivative

SEeliger, LohmanN.

(5b) Appendicularia as a neotenic derivative from ascidian.

BARRINGTON.

(5c) Appendicularia as a neotenic derivative from thaliacean

Garstang.

\section{CONSIDERATIONS ON THE TUNIGATE ORGANIZATION}

Coeloms and metamerism: Garstang and Lohmann, either, did not admit any trace of metamerism in the tunicates, although the former regarded the neuromuscular relations found in the tail of ascidian larvae and appendicularians as the incipient metamerism (of the secondary nature) but not the vestigial metamerism.

Regardless of the presence or absence of any spaces, the mesoderm formation in the tunicates is carried out in the way just the same as in the Cephalochordata that forms evidently the series of small coeloms which will, however, become quite obsolete with the development of muscles on the coelom wall. At least, the ancestral tunicates must have coeloms as suspected by IHLE and BARRINGTon. In addition to the pericardium, the epicardium can be regarded as a homologue of the coelom. GARSTANG (p. 156) rejected the interpretation of the epicardia as modified coclomic diverticulae (possibly collar cavities according to SEELIGER), because all evidences of a developmental connection of the epicardia with the pericardium were withdrawn. It seems, however, very questionable that the connection between the epicardia and pericardium is decisive at defining the nature of epicardia, because the formation of coeloms is carried out indeed in a variety of ways quite different from one another in the enteropneusts that are seemingly closely related with the chordate ancestry. 
The finding of Ivanov that Siboglinum caulleryi, a pogonophore, is provided with in the posterior distal part of body about 23 segments which resemble evidently the metamerism in the posterior portion of the body in the postlarval stage of Annelida on one hand and the sencodary segmentation in the Acrania and Vertebrata on the other hand, seems to show that the ancestral enteropneust, which must be closely related with the Pogonophora, was a segmented worm. Then, the opinion of Gutmans that the myomeric structure of fishes was derived from the metameric coeloms of precursing segmented animals of fishes seems to justify the supposition that the metamerism seen in the chordates is not of a secondary feature, but an intrinsic structure. It is highly possible that the whole animals above the level of the ancestral annelid have been primarily segmented. The body of Doliolum and Salpa is provided with ring muscles which are originated from the "Wurstförmigen" mesodermrings that remind us of mesodermal foldings to form the series of segmental coeloms. If the ancestral primitive tunicates were provided with coeloms and retained the metamerism, then the doliolid and salp must be regarded as conserving the primitiveness in this respect, especially the former because of higher regularity of its muscles. In my opinion, budding of the stolo prolifer is seemingly related also with the segmentation as it will be explained later.

Tail: Hyman warned us to be careful at estimating the phylogenetic significance of pelagic larvae, because there might be some larval adaptation independent of phylogeny as seen, for instance, most prominently in such nurses as pilidium, bipinnaria, and plutei. It is true that the pelagic larvae do not need the pelagic ancestors as stated by Garstang. On the other hand, the larval development must really be a necessary process to complete the adult morphology. In this respect, at least some parts of the larval development are acceptable as the reminiscence of phylogeny, if some animals with the organization corresponding to or closely related to that found in such stages are actually existing. Against the earlier researchers and most of German specialists, Garstang and his successors who are supporting the sessile tunicate ancestry regard the tailed-larvae of tunicates as a larval form newly acquired in this animal group, and the pelagic chordates as being derived from this type of larva by neotenic evolution. It seems to me, however, that the formation of the tail was one of the most significant events in the progressive evolution from the Hemichordata to the Chordata and then the existence of a tailed-larva in the tunicates is indeed a very important phylogenetic matter as already noted far ago by DARWIN.

There have been reported some cases of the displacement of the anus from the posterior end of the elongate body to the anterior ventral surface. It is a well-known fact that in the Chaetognatha of Deuterostomia the anus opens later on the ventral surface nearly at the middle of the rudimentary alimental canal running through the body to the posterior end. SGHöpfER-STERRER (1969) reports recently the forward movement of the anus in a gastrotrich, Chordodasys riedli. In the case of the Chaetognatha, the endodermal tissue after the anus will change into the longitudinal septum 
of the tail segment. While, it is very suggestive that in Chordodasys the tissue of the postanal alimentary canal will become to be a chordoid organ consisting of articulate pieces and functional, together with some striped muscles, as a locomotive organ. SAHÖPFER-STERRE refers in the same paper to the formation of a chordoid organ from the endoderm, which is seen in the anterior portion of the alimentary canal of a turbellarian, Polystiliphora filum Ax. The production of the true endoskeletal cartilage tissue itself is not limited to the chordates but also found in some invertebrate, for instance at the anterior part of the body supporting the tentacular-tuft of a tube-worm, Eudistylia polymorpha, as reported by Person and MATHews (1967). Further, there is some evidence of the forward displacement of the anus, or the formation of the postanal tail in the Enteropneusta, as it is known in the young vermiform stages of Saccoglossus horsti and $S$. kowalevskii. The tail in these young worms is described as adhesive, highly contractile, rich of gland cells, and effective as an anchor while the worms are extruding their anterior body outside the burrow for respiration and feeding. All these facts mentioned above seem to suggest the phylogenetic processes of the tail formation and then of the appearance of the notochord and myomeres in the chordates.

The forward displacement of the anus might occur in the primitive hemichordate ancestry which must be the free-burrowing enteropneust-like worms wholly segmented. The tail might be changed functionally from an anchor to a locomotive organ as in the case of Chordodasys with the developments of a cartilaginous support from the postanal endodermal tissue and of muscles on the coelom wall of the postanal segments. In accordance with this process, the worm would go out of the burrow more and more, and the proboscis and collar would be reduced to form together merely the anterior portion of the body, where the central nervous system, accompanied with sensory organs, is located. The worm, then, would start a kind of serpentine motion by the aid of some propelling effect of the tail movement. The forward displacement of the anus in the tunicate line is very evident as seen in the development of appendicularians and ascidian larvae. In the former, the "Schwanzdarm" is first extended under the notochord to the posterior end of the tail, but later its tissue remains merely as the subchordal cells in adults of some species. The notochord and also myomeres might appear first in the tail of the protochordate ancestry in the era long before the middle Cambrian when Oesia disjuncta WALcotT, a fossil appendicularian, was living. In a line issued from the primitive protochordate ancestor, the formation of the notochord and myomeres might have advanced anteriorly with the increase of the activity of the worm, till a common ancestral form of the cephalochordate and vertebrate stem was completed. While, in another line, the tailed worm might enter the pelagic life and have advanced towards the planktonic adaptation. There, only a gentle motion is needed. The tail, thus, would have been reduced so that the notochord and myomeres would at last be constructed of a very limited number of cells and the metamerism of the body would become obsolete. The above-mentioned imagination 
resembles somewhat the principle of Eutely presented by MARTINI (1909) who regarded the tail of appendicularians which consists of a series of muscle cells on each side of the notochord as an example showing the simplification from the myomeres (in the cephalochordate ancestry). A certain member might fall from this line derived from the protochordate stem to the sea floor and enter the sessile life. The perfect planktonic life and of course the sessile life would have brought about the complete disappearance of the tail, and further the much less activity in such modes of life would have accelerated the reduction of the nervous system and sensory organs in the adult form.

Ciliated groove and neural gland: From the point of view that the tunicates are provided with the homologues of elements of the vertebrate hypophysis (pituitary gland), the situations of the Ascidiacea and Salpida seem to be very special. In the ascidians, the Anlage of the dorsal ganglion-hypophysis complex is a simple neurohypophyseal canal connecting the sensory vesicle to the pharynx. The posterior portion of this canal will form the dorsal ganglion and neural gland, while the opening to the pharynx will develop to the ciliated groove which might be, however, formed by secondary endodermal outfolding (at least in the case of accessory ciliated grooves open to the peribranchial cavities) as Willey (1893) considered. Seeliger and Huntsman (1913) considered the ciliated groove to be a medullary derivative, especially the latter author regarded the whole prebranchial area between the inner edge of the stomodaeum and the peripharyngeal bands as a medullary derivative. In the appendicularians, doliolids and pyrosomes, the ciliated groove and its canal (missing in appendicularians) are formed by protrusion from the nerve mass or the brain. The neural gland is missing in the Appendicularia, formed from the nerve mass in the Doliolida, or developed from the posterior ventral wall of the canal in the Pyrosomata. Only in the Salpida, the ciliated groove is formed from the anterior part of the central nervous system but finally completely separated from the nerve centre, and very strangely a pair of neural glands are formed by invagination from the pharyngeal epithelium, together with a canal on each.

\begin{tabular}{c|c|c|c}
\hline \hline Appendicularia & $\begin{array}{c}\text { ciliated groove } \\
\text { from the right side of } \\
\text { brain }\end{array}$ & strand & neural gland \\
\hline Doliolida & $\begin{array}{c}\text { from the anterior side } \\
\text { of brain }\end{array}$ & $\begin{array}{c}\text { from the ventral side } \\
\text { of brain }\end{array}$ \\
\hline Pyrosomata & $\begin{array}{l}\text { from the anterior side } \\
\text { of brain }\end{array}$ & $\begin{array}{l}\text { from the postero-ventral } \\
\text { wall of canal }\end{array}$ \\
\hline Salpida & $\begin{array}{l}\text { from the anterior } \\
\text { side of brain }\end{array}$ & $\begin{array}{l}\text { from the pharyngeal } \\
\text { epithelium }\end{array}$ \\
\hline Ascidiacea & $\begin{array}{l}\text { medullary, or endo- } \\
\text { dermal derivative }\end{array}$ & $\begin{array}{l}\text { absent } \\
\text { frome nenterion end of sensory vesicle }\end{array}$ \\
\hline
\end{tabular}


The vertebrate hypophysis consists of the adenohypophysis invaginated from the preoral ectoderm and the neurohypophysis extended from the floor of the interbrain (diencephalon). As both the medullary tissue and the brain are derived from the ectoderm, the Doliolida and Pyrosomata may be regarded in respect to the elements of the vertebrate hypophysis as being situated nearest to the main stem to the Vertebrata, while the Salpida and Ascidiacea and probably also the Appendicularia are most specialized. As the potentialities of the tunicate germ layers are very plastic, the difference of germ layer may be put aside, but the formation of the ciliated groove in the ascidians and of the neural glands in the salps by invagination of the pharyngeal epithelium seems noteworthy when the nature of the buccal diverticulum of the hemichordates is considered.

The diverticulum is never regarded as a rudimentary notochord in these days. KomaI (1951) is suggesting the resemblance between the diverticulum and the ciliated groove and its duct of tunicates, which are probably homologous to the anterior lobe (adenohypophysis) of the vertebrate hypophysis. Hyman, however, supported rather the opinion of SILÉN (1954) that the diverticulum represents ancestrally some sort of preoral gut (p. 200, lines 29-32). In my opinion, both of the suggestions presented by Komai and SiLÉn seem to be acceptable. In the enteropneusts which are provided with the proboscis at the anterior end of body to maintain their burrowing life, the mouth must necessarily be moved posteriorly and then the anterior portion of the gut anterior to the newly open mouth would remain first simply as a buccal diverticulum without any significant function. As seen in the formation of the ciliated groove in some ascidians and of the neural glands in salps possibly by endodermal invagination, a chemoreceptive function might be imposed upon this diverticulum. In the progressive evolution along the chordate stem, the function would have changed to be endocrinous and the germ layers concerned would have been fixed definitely as they are seen in the vertebrates. Anyhow, the variety in the tunicates of the processes of forming these exactly the same structures may be noted just as the variety seen in the coelom formation in the enteropneusts. The corresponding structures are not developed in the cephalochordates so well as in the tunicates, possibly this is related with the semi-sedentary mode of life in the cephalochordates which are retrograded from or left behind the evolution on the line to the Vertebrata.

Budding: The ability of budding prevailing in the tunicates has been regarded as a sign of the primitiveness of this animal group (VAN NAME 1921, Garstang 1928, LOHMANN 1933). Further, budding in the tunicates was regarded as an inherited nature from the sessile ancestry and the actual ways of budding were acquired independently in respective groups in the tunicates (Grobben 1882, Hartmeyer 1918, GarstanG 1928). Garstang suggested that budding in the tunicates was originated from the renewal of the pharynx and peribranchial cavity (atrium) and thus the stolo prolifer was constituted primarily of the epicardial and atrial outgrowths which would be corresponding to the undifferentiated material for the pharynx and peribranchial 
cavities. This is a very fascinating idea. However, the ability of budding itself will never mean the primitiveness, but only the simpleness or the lower degree (not primitive!) of organization which may be brought about by simplification that is then a face of specialization. The potentiality of budding may be considered to be a universal nature throughout the animal kingdom, if the continuity between it and the regenerative ability is admitted to some extent (VAN Name 1921). Only the appearance of budding is limited actually by some higher degree of organization, such as the larger body size accompanied with highly complicated body structures or the appearances of the well developed or specialized external covering of the body or some specialized body organs, for instance the definitive liver in the alimentary system. Budding is seen generally, not only in primitive acoelomates but also in some coelomates such as the Annelida, Tentaculata, Echinodermata, and Hemichordata. It is not limited to the sessile animals, but also occurs in the free-living forms, too, as seen in some polychaetes, sea-stars, brittle-stars and enteropneusts (see Balanoglossus capensis, GiLanRist 1923). It is to be noted that in the segmented animals budding is necessarily associated with segmentation. The segmentation itself is primarily the repetition of the same body structures. Then in the segmented animals of simpler body structures, it is highly probable that respective segments or groups of some segments may easily regenerate the perfect animal body.

Now, some of the primitive chordate ancestry, which were segmented and provided with the tail, entered the stem of the urochordata and acquired a pelagic (leading to planktonic) life, then the reduction would occur in the formation of the tail and its metameres. On the other hand, the pharynx tended toward a prominent growth. Being oppressed anteriorly by the pharynx increasing the size rapidly and posteriorly by the tail reducing, the most prominent part of the body, of course segmented and originally situated between the pharynx and anus, lost its domain by and by. This oppressed body part might have found the space and way to reveal its potential metamerism in the formation of the stolo prolifer. There, the metamerism might be shown as a series of coeloms formed by successive constrictions of the epicardia which are a pair of coeloms outpouched from the gut as seen in some tornaria. The stolo prolifer might thus be an extension of a segmented body part and be obliged to grow out from the postero-ventral part of the pharynx, because the space straight posterior to the pharynx was occupied by the tail which was still remaining, but reducing and refusing to accept the stolo. Thus, the stolo had to include originally a set of important body elements within it, and consequently each segment or rather each group of some segments. would be qualified to grow up to a perfect individual when it was liberated from the distal end of the stolo, just like the case seen in some syllids. Asexual reproduction of Balanoglossus capensis from the posterior distal portion of the body is very suggestive, because possibly the invisible metamerism might be retained there as seen in the pogonophore, Siboglinum caulleryi.

GaRstang (1928) explained very convincingly the relationships among the dif- 
ferent ways of budding in the tunicates, and I cannot but admire the reasonability of his opinion and follow him. He combined the thoroughness of stolonial elements with the primitiveness of budding way and considered the Thaliacea to be more primitive in regard to budding than the Ascidiacea. Actually the stolo prolifer of the Thaliacea is made up very thoroughly, especially in the doliolids it comprises seven elemental strands: a pair of epicardial strings, a pair of primary cloacal (of peribranchial cavities) strings, a secondary cloacal (of atrial cavity) string, a mesodermal string, and a cardiac string. Either of extensions of the peribranchial cavities (atria) and epicardia may be lost in some ascidinas and at the extreme of the botryllids budding is performed simply by the epithelium of the external wall of the peribranchial cavity, or further even by using the mesenchymal and lymph cells as the main material, whose nature is probably mesodermal. It is quite natural that budding is checked in highly specialized appendicularians and most of solitary ascidians which are large-sized and protected externally with a highly developed test which might be effective as a kind of exoskeleton.

\section{LARVAL MODIFICATION AND NEOTENIC EVOLUTION}

As to the phylogenetic relationships in and around the Tunicata, the larval modification or the acquisition of some new morphology by larvae and the neotenic evolution have been frequently taken up as the mechanisms to explain the evolutionary processes concerning the Tunicata. The most important points to be considered first about these phenomena secm to me to be the following two: the first is the possibility of the progressive evolution in firmly fixed animals and the last is the range of the morphological modification in pelagic larval forms.

Looking through the animal kingdom, from the Protozoa through Vertebrata, the free-moving mode of life seems to be essential. There are indeed many sessile animals, some of their representatives are found even in the Arthropoda and Mollusca. Although BARrington seems feeling some difficulties to accept that sessile habits have evolved independently in several different lines within the Deuterostomia (p. 13, lines 19-22), it is evident that the sessile life had been acquired quite independently and convergently in many different and separated animal groups merely as a specialized mode of life and it will never be stimulative in the progressive evolution. On the other hand, the groups of sessile forms are usually regarded as being at the end of a blind branch in evolution. None of the sessile animal groups can be combined straight with any animal groups of higher grades on the course of evolution. In other words, the main roles in the progressive evolution in the animal kingdom have seemingly been played solely by free-moving forms. The phylogenetic relations between the Tunicata and other animal groups can not be exceptional.

I cannot deny absolutely the neotenic evolution. Retaining of larval morphology, then the combination of larval morphology and sexual maturity, and lastly the dis- 
appearance of adult morphology are theoretically not impossible. These may occur in some sessile animals. However, the morphological modification during the main pelagic larval life is seemingly very limited. The planktonic life in the open sea is extremely stable and seemingly much less stimulative than the nektonic life or freemoving life on the substratum. Excepting some special animal groups differentiated solely as plankters such as radiolarians, rotifers, and cladocerans, etc., every group of plankton animals is always much less dominant than every corresponding groups of partners living freely on the sea floor. For instance, the calanoid copepods are the most significant animal plankters of the sea, but the number of their species is incomparably smaller than that of non-planktonic harpacticoid copepods. It is not impossible but improbable that the morphological modification so large enough as to achieve the progressive evolution to any higher organization deserving of another separate phylum will occur in the planktonic larval stage in the sea. The morphology of pilidium, actinotrocha, bipinnaria, or plutei, etc., is indeed a result of surprising modification, but yet the principle of modification in respective larvae is primarily limited to the process to achieve their adult morphology rapidly or economically from the general larval morphology very primitive and adapted for the planktonic life and micro-organism feeding. For these reasons, if there are some alternatives, I will tend to hesitate to accept the neotenic evolution in and around the Tunicata.

Any modifications occurred during the planktonic larval stage and of a phylogenetic significance are seemingly achieved, in order to fit the demands in adult, under stress of some trends appeared in the adult morphology or behaviour mutationally or to adapt to the different circumstances; though it is far beyond my ability to mention something about the extreme mechanism. Theoretically no morphological modification can occur in adults built up definitely, the specific modifications will occur generally in the last stage of development as mentioned in his theory of Hypermorphosis of DE BEER, but I don't think that any specific modification in the final stage of development can be explained as a larval modification responsible for the neotenic evolution.

\section{CONGLUSIVE SPEGULATION}

(1) Protochordate ancestry: As stated above, the free-swimming ancestry of the Protochordata and of the Tunicata is supported here. I agree with BonE (1960) in placing the Hemichordata in the chordate-line, though the imaginary evolutional processes differ much between his and mine. A free-living and wholly segmented primitive ancestral enteropneust with a tendency to go out from the burrow onto the sea floor in its behaviour and a trend towards the forward displacement of the anus in morphology was seemingly the form antedated the primitive ancestral protochordate.

GARSTANG, who suggested the sessile protochordate ancestry, regarded Cephalodiscus as a living proof of his suggestion, as it bears the gill-slits in the simplest state 
together with an external lophophore. However, the appearance of the tentacular appendages and then the reduction of the gill-slits with the change of the food material and with the increase of respiratory capacity of the tentacles would be brought about very easily by a sessile life, especially the former is seen convergently in many different animal groups.

The primitive ancestral protochordate bore, in addition to the series of gillslits which were U-shaped, tongue-barred, and synapticulate, the tail which was provided with the notochord and myomeres, both were tending to extend forward into the trunk; the nerve-tube was steadily developing and the precursors of the hypophyseal elements were developing, too. The formation of the mesodermal Anlage by outfolding from the dorso-lateral side of the archenteron might be included in the features characteristic to the protochordate stem. The pharynx had developed prominently for the purposes of respiration and feeding and for the latter the endostyle appeared on the middle of the bottom of the pharynx. The atrium was formed, but it was very simple. The heart had moved from the dorsal to the ventral side. This was, however, not a very big modification, because as suggested already by LoHmann the heart of such a simpler structure as seen in the Hemichordata, Cephalochordata and Tunicata, would be located naturally at the site least affected by the movement of the body.

(2) Tunicate ancestry: Entering the pelagic life, the growth of the pharynx started and the reduction began in the tail and general metamerism. The ancestral primitive tunicates might be still free-swimming, but showing a prominent trend towards the adaptation for the perfect planktonic life. It was retaining still the tail significantly reduced and provided with some vestigial metamerism in the trunk. On the other hand, the reduction of body coeloms and metameres was replaced by the appearance of the epicardia and the development of budding of the stolo prolifer. The gill-slits were reduced, too, to the series of simpler elongate slits situated perpendicularly to the body axis. The atrium was formed by the union of a pair of cavities formed respectively by lateral envagination along the outside of the pharynx. Mainly for feeding, the pharynx had increased the size, occupying at least the anterior half of the body. The body surface acquired an ability of secreting a gelatinous substance to protect the body and at the same time to enhance the bouyancy as seen generally in planktonic animals. The nerve-tube had reduced, too, because of much less active mode of life as a plankter.

(3) Separation of appendicularians: The line of appendicularians was issued first from the above-mentioned tunicate ancestry, with the decrease of the body size and the space of the atrium, the development of preoral collection of food-particles together with the increase of the tail size (not the progressive modification of the tail structure) to maintain this feeding mechanism and a controlled locomotion, and the maintenance of the sensory vesicle of the central nervous system for the special mode of life supported by somewhat active tail movement. For such high specialization, the ability of budding and naturally the formation of the stolo prolifer had been 
completely checked in this line. The gill-slits were redcued to a pair of spiracles. (4) Ancestral doliolids: After the appendicularian line was issued, the anus was moved to the dorsal side and then the atrial aperture was displaced to the dorsoposterior side of the trunk; this was to spare the ventro-posterior side of the trunk for the reducing tail and developing stolo prolifer. The nerve-tube and sensory vesicle were wholly degenerated in the adult form, although the statocyst was still remaining. The metamerism in the trunk was still conserved as the regular muscle bands. Budding well developed to form a kind of colony on some part of the body. The site of the colony would have moved from near the ventral stolo to the dorsoposterior side of the body through the right side along the line of doliolids. Polymorphism occurred among the zooids of colony, till the complicated life history of extant doliolids was completed. Doliopsis is evidently a specialized form of the doliolids, closely related with the trophozooid of colony formed on the dorsal protuberance of oozooid. In addition to the progress along the above-mentioned line to the recent doliolids, the ancestral doliolid issued two other lines: one was the line to the salps and the other to the ancestral pyrosoma.

(5) Salps: It may be accepted generally that the salps were derived from the ancestral doliolid. The vestigial metamerism on the trunk is still remaining, but the arrangement of ring muscle bands has lost its regularity as compared with the doliolids. The morphology of Doliopsoides may be accepted in a way as an intermediate between the typical doliolids and salps. The asexual reproduction by budding of the stolo prolifer has become much simpler than in the doliolids, but this can never be taken as the primitiveness, it may be the result of simplification, namely a face of specialization. The development of the embryo at a kind of placenta is also an example of specialization in this animal group. The formation of the neural glands by pharyngeal envagination may be taken as another example. The embryonic development in the mother body must have induced the loss of the larval tail.

(6) Ancestral pyrosoma: Some researchers (Vogt, Gegenbaur, Grobben, Uluanin) regarded Doliopsis as an intermediate form connecting the Doliolida to the Pyrosomata. This relation was suspected because of their resemblance in the appearance of body muscles which are much reduced. However, it is very questionable that such a rather superficial resemblance can really be of a phylogenetic significance; the reduction of the muscles itself might be the result of the fixed life of zooids in the colony, if a close relation between Doliopsis and the trophozooid of doliolids is admitted. The formation of colony on some part of the trunk in the ancestral doliolids had developed a different pattern of life history which comprised the trend toward the reduction of oozooid and the increase of the colony size. The larva of the ancestral pyrosoma was still retaining the tail, and the oozooid retained the body structure and body size, similar to those of the blastozooid. Of course, the firmly fixed life brought about the reduction of the body muscles. The antero-posterior situation of the branchial and atrial apertures was retained in respective zooids as in the ancestral doliolids. This 
ancestral form of pyrosoma specialized itself to the recent pyrosoma on one hand, but on the other hand issued a line of the Ascidiacea tending towards the sessile life. The recent pyrosoma is characterized principally by its unique hollow cylindrical colony and the reduction of the oozooid to cyathozooid.

(7) Ascidiacea: Settling down of the colony of some ancestral pyrosoma might occur before the colony was furnished with an ability of locomotion gentle but sufficient to support its planktonic life. The contact of the colony to the sea floor and then its permanent settlement on the substratum must have pressed the zooids to take only the free surface of the colonial mass and made the common cloacal cavity take a complicated canal system communicated externally through some common cloacal apertures. The site of the atrial aperture would be moved in relation to the development of the new canal system to open to the space ultimately leading to the exterior; thus the atrial aperture have tended to move much anteriorly, very close to the branchial aperture, till at last both apertures open to the exterior straight in some forms. However, most parts of the alimentary canal, excepting the pharynx, were left posteriorly to form the abdomen in most of the extant compound ascidians. To enhance the efficiency of the pharynx for feeding and respiration in the sessile state, the gill-slits were subdivided into a number of stigmata. The differentiation of the colony has tended to two directions: one was the trend toward a variety of systems of zooids and the other toward the variability of the size of zooids. The increase of the size of zooids was accompanied with a trend toward the separation of respective zooids, and thus the compound ascidians issued some social ascidinas, some of which developed to the solitary ascidians that are provided with a fully developed large branchial sac, furnished complicatedly with vessels, and a highly developed external test over the body surface, which might be effective as a kind of external skeleton. The perpendicular orientation of zooids in the compound ascidians have changed to horizontal in the solitary ascidinans, with the ventral side toward the substratum; and with this the intestinal loop, together with the gonads, has moved from the posterior in the "merosomen" state of the compound ascidians to the side (mainly the left, but the right in Corellidae) of the branchial sac in the "holosomen" state of the solitary ascidinans. The ability of budding is checked generally in the solitary forms in the "holosomen" state.

(8) General considerations: Throughout the above-given figures of ancestors, it is suggested here that the protochordate ancestor was derived from the ancestral enteropneust having the series of gill-slits. Namely, the present speculation may be accepted merely as a modified explanation of the classical "Wurmtheorie". As Hyman stated (p. 201) the similarity of the gill-slit between the enteropneusts and amphioxus is inconceivable except on the basis of a common ancestry. Garstang regarded the formation of atria in the tunicates, which takes place before the formation of gill-slits, as a developmental order quite according with the phyletic history of the protochordates (p. 52), and thus rejected the retrograded situation of ascidians 
from any pelagic ancestral protochordates without the atrium or with the atrium appearing after the formation of gill-slits. However, this is regarded here as merely a modification in the developmental processes to attain the adult morphology. In connection with this, it will remain as a question whether or not the atrium of protochordates is referable to the series of gill-pouches in the enteropneusts. It is needless to explain that the ascidian ancestor needs not bear only two or three pairs of gill slits as mentioned by Garstang.

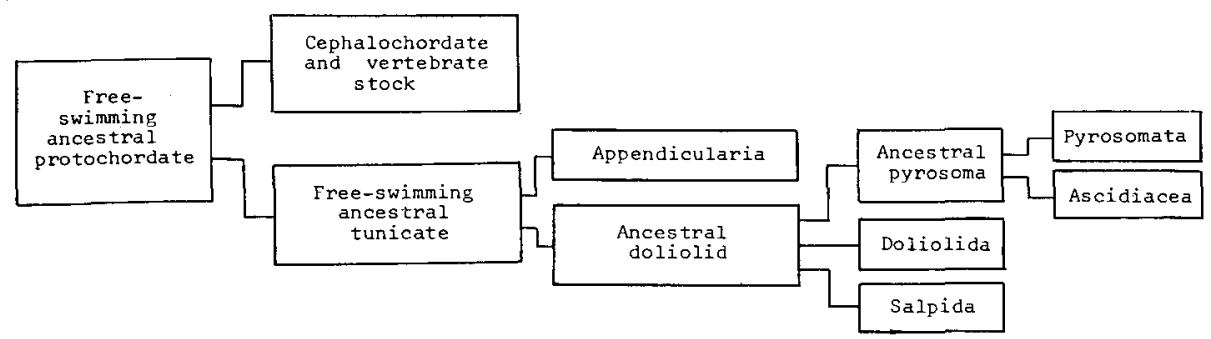

Diagram 3. Phylogeny of the Tunicata, presented in this paper.

As the ancestral tunicate is supposed here as a derivative from a free-swimming ancestral protochodate, the ascidian tailed-larva cannot be only a very specialized form for habitat-selection, but primarily an interpolation reminiscent of the ancestral morphology. As seen in many different sessile or sedentary animals such as nemerteans, kamptozoans, bryozoans, phoronis, and echinoderms, etc., the metamorphosis somewhat drastic is a common feature in their larvae, this is quite natural to achieve in a limited time-span their adult morphology which must have been acquired quite independently by orthogenesis, mutation or adaptive modifications unique to respective animals. Retaining of the chordate nerve-tube in ascidian larvae and the replacement of it by a much simpler nervous system in ascidian adults can be nothing but only an example of such metamorphoses mentioned above and therefore without any profound phylogenetic significance of creating the chordate nerve-tube in the larval life. The free-swimming larvae of ascidians are very short in their larval life as compared with that of other sessile or sedentary animals and do not show any sign of feeding. BARRINGTON considers this as showing the specialization of larvae adapted to habitat-selection. If any kind of specialization were done in ascidian larvae for habitat-selection, it would have to be first an extension of the larval life. On the contrary, the free-swimming life is extremely limited in ascidian larvae, and this must be, in my opinion, thought in the correlation with the highly mosaic development of earlier embryos of ascidians. Further, a few elements of body organization can be traced back even to parts of the fertilized egg. All these are seemingly nothing but a shortening process to achieve the morphology of adult ascidians which must be greatly specialized, for primarily free-swimming protochordates, to adapt to the sessile life. The mosaic development of earlier embryos in ascidians is to be noted 
in the correlation with a very short larval life in these animals, but not in relation to the asexual budding ability (see Watanabe, 1970, p. 172).

The stem of the Tunicata issued first the Copelata and evolved to the level of the ancestral doliolid which was seemingly the common ancestor of the Acopa and issued two lines respectively leading to the salps and ancestral pyrosoma, besides a line developing to the recent doliolids. The ancestral pyrosoma, then issued the line leading to the compound ascidians, in addition to the line to the extant pyrosoma. Consequently the doliolids and salps are related with each other closely to form together the group Thaliacea and pyrosoma intermediates between the Thaliacea and Ascidiacea. Both the salps and ascidians show some very specialized morphological characteristics, such as the features of gill-slits and the formation of ciliated groove or grooves, neural gland or glands, and of connecting canal or ducts. The development of oozooid at the placenta of blastozooid must be another specialization in the salps.

The primitiveness in both the Appendicularia and Doliolida (Cyclomyaria) was already noticed by GARSTANG, of course together with their specialization; this was expressed as a mixture of larval and adult characters. Then comes the phyolgenetic combination of the appendicularians and doliolids. Garstang compared the nonoikoplastic area of appendicularians to the wall of shallow atrio-cloacal cavity of doliolids and reached the conclusion that the reduction of the atrio-cloacal cavity and the eversion of the epithelial lining of the cavity in doliolum produced the morphology of the trunk of appendicularians, something like the case of trophozooid of doliolum, and then the dorsal hood in some Oikopleura (for instance, O. longicauda) is homologous to the dorsal outgrowth of the oozooid of doliolum. His explanation is very convincing. In addition to this, the nerve-cord is running posteriorly along the right side of the oesophagus in both the appendicularians and doliolid larvae. Further, the exuviation and renewal of the doliolid test was reported by ULJANIN, this reminds us of the appendicularian house which is renewed at intervals. The statocyst remains still in the appendicularians and doliolid oozooid. The tail of the appendicularians is rotated anticlockwise by 90 degrees from its original dorsoventral situation. If a similar rotation of the larval tail had occurred in doliolum and induced a rotation of the postero-ventral part of the trunk just adjoining the base of tail, then the atrial aperture and possibly the posterior part of stolo, too, would be moved somewhat dorsads. In this case, the migration of the posterior part of stolo must be performed on the right side of the trunk. The dorsal situation of the atrial aperture and the dramatic travelling of buds from the ventral stolo to the dorsal through the right side of the body in doliolum might be induced under the press of some potentiality of such a rotation which is, however, never observed actually in highly reduced tail of doliolum larvae.

The line of the Cephalochordata was probably issued from the stem from the ancestral protochordate to the Vertebrata, after the line of the Tunicata was derived 
from the stem, and left behind the progressive evolution because of their semi-sedentary, much less active behaviour. The Pterobranchia is regarded here as a specialized hemichordate derived from the free-burrowing primitive enteropneust and adapted to the sessile life.

The present speculation can never be wholly original, because partially explained by different authors even repeatedly. The only important point must be that it is constructed wholly rejecting the significant progressive evolution of sessile forms and the so-called larval evolution. This is because of my own subjective judgment on the biological aspects and processes maintained in and by extant animals. All the above-mentioned evolutional processes must have been over in very early era before the middle Cambrian, and practically no fossils are available to prove these. Then, the biological aspects and processes maintained in and by extinct ancestral protochordates must be far beyond my imagination. Therefore, I want to close the present speculation, as done already by previous authors, by the following words "The nature might have moved on the course quite different from the present speculation".

\section{REFERENCES}

Barrington, E. J. W. (1965): The biology of Hemichordata and Protochordata. 176 pp., Oliver and Boyd.

Berrill, N. J. (1950): The Tunicata, with an account of the British species. 354 pp., The Ray Society.

Bone, Q. (1960): The origin of the chordates. Jour. Linnean Soc. London, Zool., vol. 44, no. 297, pp. 252-269.

DArwin, Ch. (1874): The descent of man and selection in relation to sex. Second edition. John Murray, London.

Garstang, W. (1928): The morphology of the Tunicata, and its bearing on the phylogeny of the Chordata. Quart. Jour. Microsc. Sci., vol. 72, part 1, pp. 51-187.

Grlchrist, J. (1923): Dimorphism and asexual reproduction in Ptychodera capensis. Jour. Linnean Soc. London, Zool., vol. 35.

GrobbeN, C. (1882): Doliolum und sein Generationswechsel. Arbeiten aus dem Zool. Inst. Univ. Wien.

Gutmann, W. F. (1966): Die Funktion der Myomere in phylogenetischer Sicht. Senckenberg. Biol,, vol. 47, part 2, pp. 155-160.

(1969): Acranier und Hemichordaten, ein Seitenast der Chordaten. Zool. Anz., vol. 182, no. $1 / 2$, pp. 1-26.

Hartmeyer, R. (1918): Eine wiedergefundene Ascidie. Sitzungsber. Gesell. Nat. Freunde Berlin, 1918, pp. 395-396.

Herdman, W. A. (1904): Ascidians and amphioxus. Cambridge Natural History, vol. 7, pp. 33-138.

Huntsman, A. G. (1913): On the origin of the ascidian mouth. Proc. Roy. Soc. London, Ser. B, vol. 86 , pp. $454-459$.

Hyman, L. H. (1959): The invertebrates, smaller coclomate groups, vol. 5, 783 pp.

Irle, J. E. W. (1935): Desmomyaria. Kükenthal und Krumbach: Handb. d. Zool., 5, part 2, pp. 401-532.

Ivanov, A. V. (1965): Structure de la region posterieure setigere du corps des pogonophores. Cahiẹs de Biol, Mar., vol. 6, no. 3, pp. 311-323, 
Komai, T. (1951): The homology of the notochord in pterobranchs and enteropneusts. American Naturalist, vol. 85, pp. 270-271.

Lohmann, H. (1923): Oesia disjuncta Walcott, eine Appendicularie aus dem Kambrium. Mitteil. Zool. Staatinst. Zool. Mus. Hamburg, vol. 38, pp. 69-74.

(1933): Tunicata, allgemeine Einleitung in die Naturgeschichte der Tunicata. Kükenthal und Krumbach: Handb. d. Zool., vol. 5, part 2, pp. 3-14.

(1933): Appendiculariae. ibid., pp., 15-202.

Martini, E. (1909): Über Eutelie und Neotenie. Verh. d. Deutsch. Zool. Gesellschaft, vol. 19, pp. 292-299.

Metcalf, M. M. (1918): The Salpidae: A taxonomic study. U.S. Nation. Mus. Bull. 100, vol. 2 , part 2.

Neumann, G. (1934): Erste Unterklasse der Acopa, Thaliaceae. Kükenthal und Krumbach: Handb. d. Zool., vol. 5, part 2, pp. 203-225. (1934-35): Pyrosomida. ibid., pp. 226-323. (1935): Cyclomyaria. ibid., pp. 324-400.

Person, P. and M. B. Mathews (1967): Endoskeletal cartilage in a marine polychaete, Eudistylis polymorpha. Biol. Bull., vol. 132, no. 2, pp. 244-252.

Romer, A. S. (1967): Major steps in vertebrate evolution. Science, vol. 158, no. 3809, pp. 16291637.

SGHÖPFER-STERRER, Ch. (1969): Chordodasys riedli gen. nov., spec nov., a macrodasyoid gastrotrich with a chordoid organ. Cahiers d. Biol. Mar., vol. 10, no. 4, pp. 391-404.

Seeliger, O. (1885): Die Entwickelungsgeschichte der sozialen Ascidien. Jenaische Zeitschrift f. Naturwissensch, vol. 18.

(1893-1907): Tunicata in "Bronn's Klassen u. Ordnungen des Tier-Reichs", vol. 3, suppl.

SiLÉn, L. (1954): Reflections concerning the stomochord. Proc, Zool. Soc. London, vol. 124, pp. 63-67.

UlJanin, B. (1884): Die Arten der Gattung Doliolum im Golf von Neapel. Fauna und Flora des Golfes von Neapel, no. 10.

VAN NAME, W. G. (1921): Budding in compound ascidians and other invertebrates, and its bearing on the question of the early ancestry of the vertebrates. Bull. American Mus. Nat. Hist., vol. 44, pp. 275-282.

WALcotT, Ch. D. (1911): Cambrian geology and palaeontology II. No. 5. Middle Cambrian annelids. Smiths. Miscell. Coll., vol. 57, pp. 132-133.

Watanabe, H. (1970): Ascxual reproduction in compound ascidians I-II. Zool. Mag. Tokyo, vol. 79, nos. 5-6, pp. 131-143, 163-174. (in Japanese)

Willey, A. (1893-94): Studies on the Protochordata I-III. Quart. Jour. Microsc. Sci., vol. 34, pp. 317-360; vol. 35 , pp. 295-333. 